\title{
O DUELO ENTRE MATERIALIDADES: A REPRESENTAÇÃO DA VIOLÊNCIA NO CONTO “O DUELO”, DE GUIMARÃES ROSA, E NO FILME HOMÔNIMO, DE PAULO THIAGO
}

\author{
Juliana Marschal Ramos ${ }^{1}$ \\ Lívia Stumpf ${ }^{2}$ \\ Cristiane da Silva Alves ${ }^{3}$
}

\begin{abstract}
Resumo: A literatura é uma forma de expressão da realidade e do cotidiano, que são tecidos por diversos fios, sendo um deles o da violência. Este trabalho tem como objetivo analisar a representação da violência por meio da escrita e por meio audiovisual do conto "O duelo", publicado na obra Sagarana, de Guimarães Rosa, e na adaptação cinematográfica homônima, dirigida por Paulo Thiago. Por meio de um estudo de cunho bibliográfico e de método comparatista, foram analisadas as ocorrências de atos violentos em ambas as materialidades à luz de pesquisadores como Alves (2003), Brito (2006) e Hutcheon e O’Flynn (2013). É possível perceber que essa adaptação gerou modificações para que o sentido da obra fosse mantido, mas adicionando alguns elementos, como a inserção de personagens de outros livros. Palavras-chave: Guimarães Rosa; Literatura e cinema; Violência.
\end{abstract}

Abstract: Literature is a way of expression of reality and daily life, which are woven by several threads, one of them is related to violence. This work aims to analyze the representation of violence through the writing and audiovisual media of the story "O duelo", published in the work Sagarana, Guimarães Rosa, and the film adaptation, directed by Paulo Thiago. Through a bibliographical study and comparative method, the occurrences of violent acts in both materialities were analyzed in the light of researches by Alves (2003), Brito (2006) and Hutcheon and O'Flynn (2013). It is possible to perceive that this adaptation resulted in some modifications in order to maintain a similar meaning, but also inserting some elements, such as characters from other books.

Key-words: Guimarães Rosa; Literature and cinema; Violence.

1 Graduada no curso de Licenciatura em Letras Português, Inglês e suas respectivas literaturas pela Universidade Feevale (2018) e graduanda no curso de Bacharelado em Letras Português, Francês e suas respectivas literaturas pela Universidade Federal do Rio Grande do Sul (UFRGS).E-mail: julianamarschalramos@gmail.com

2 Formada em Jornalismo pela PUCRS e graduanda no curso de Bacharelado em Letras Português/Espanhol e suas respectivas literaturas pela Universidade Federal do Rio Grande do Sul (UFRGS).E-mail: liviacstumpf@gmail.com

3 Doutora em Letras pela Universidade Federal do Rio Grande do Sul (2016). E-mail: cristianesalves@gmail.com 


\section{INTRODUÇÃO}

A literatura pode ter papel fundamental na formação dos indivíduos. Tornquist discorre que "como representação da vida, a literatura é o lugar em que a vida, em toda a sua complexidade, social e subjetiva, vai se expressar" (TORNQUIST, 2012, p. 111). Dentre tantos aspectos da vida que podem ser representados, a violência é um desses fios que tecem o cotidiano. De acordo com Kun, Conte e Oliveira (2013), o signo da violência é presente na sociedade brasileira, apontando que duas possíveis causas para esse início seriam a colonização e a escravatura. Nesse caso, o domínio sobre o outro é caracterizado como um ato violento.

Nas obras de Guimarães Rosa, a violência é um tema muito presente ao longo das narrativas. É possível refletir sobre o surgimento da violência em decorrência da falta de lei oficial, como a polícia, por exemplo. Contudo, mesmo quando esses estão presentes, atuam através da violência, o que Alves (2013) definiria como "violência autorizada", já que seria amparada pelas leis por ter o objetivo de defender e proteger os cidadãos. Além disso, o sertão por vezes surge não somente como espaço de eclosão da violência, mas como instância capaz de gerá-la, alimentá-la, permitir que ela se instaure como em um reino sem limites, em que a desordem converte-se em única ordem possível, no qual o desmando é a lei respeitada. É comum, também, perceber que pela falta de lei do Estado leva a criação da lei dos homens. Quanto a isso, podemos relembrar os jagunços do Grande Sertão: Veredas reagindo à morte de Joca Ramiro por meio de vingança.

Pensando nas relações entre literatura e violência, este trabalho tem como proposta principal analisar a representação da violência no conto "O duelo", de Guimarães Rosa, e também como ela é retratada quando passada da palavra para o vídeo, na adaptação cinematográfica de Paulo Thiago, lançada em 1973. O ato da violência aqui estudado será aquele realizado entre os homens.

A pesquisa a ser realizada é de cunho bibliográfico e utiliza o método comparativo. As acadêmicas irão realizar um estudo comparatista, utilizando teóricos como Brito (2006) e Hutcheon e O’Flynn (2013) para refletir sobre as mudanças necessárias para a adaptação do conto em filme.

Dessa forma, este trabalho será dividido em 5 seções. Primeiro, literatura e violência serão introduzidos ao leitor. Em seguida, a violência será analisada em seus diferentes contextos. A relação entre literatura e cinema também será discutida com aporte teórico de Brito (2006) e Hutcheon e O’Flynn (2013). Após, será realizada a análise do processo de adaptação cinematográfica do conto $\mathrm{O}$ duelo, dirigido por Paulo Thiago. Por fim, algumas reflexões finais serão apresentadas.

\section{“VIVER É MUITO PERIGOSO”: VIOLÊNCIA ENTRE OS HOMENS}

A violência é um tema recorrente na literatura, principalmente se pensarmos que ela representa um aspecto presente na condição humana. A obra de Rosa apresenta esse tema no contexto sertanejo. Riobaldo, narrador e personagem de Grande Sertão: Veredas, sempre 
alerta sobre os perigos de viver. Contudo, a obra escolhida para análise de um dos contos foi Sagarana, que que foi o primeiro livro publicado de Guimarães Rosa, em 1946. É composto por 9 contos longos (ou novelas). Álvaro Lins, em seu ensaio, "Uma grande estreia", fala sobre a construção da obra e afirma que ela "vem a ser precisamente isto: o retrato físico, psicológico e sociológico de uma região do interior de Minas Gerais, através de histórias, personagens, costumes e paisagens, vistos ou recriados sob a forma da arte da ficção". (LINS, Álvaro. 1991, p. 237-242)

Dentre possíveis aspectos a serem analisados, o escolhido foi a violência cometida entre os homens. No livro, alguns contos que têm essa temática são "O duelo", "Corpo fechado" e "A hora e a vez de Augusto Matraga". Além de compreender a relação da violência entre os indivíduos do contexto sertanejo na obra de Guimarães Rosa, essa pesquisa pretende relacionar a forma como a violência é retratada no conto e na adaptação cinematográfica homônima, dirigida por Paulo Thiago, lançada em 1973.

Kun, Conte e Oliveira (2013) explicam que a sociedade brasileira já vem desde a sua formação em contato com o signo da violência, citando a colonização e a escravatura como dois exemplos marcantes dessa afirmação. Além disso, eles explicam que "essa violência proporciona uma funcionalidade no cotidiano das relações que tratam como naturais mínimas transgressões e que desencadeiam uma dinâmica viciada se pensarmos na teia imagética dos processos inter-relacionais". (KUN, CONTE E OLIVEIRA, 2013, p. 244)

Dessa forma, a violência será analisada a partir de um olhar coerente ao contexto da obra, sem esquecer que em todos nesses espaços, esses atos estão presentes. De acordo com Alves (2013)

No Brasil, a violência e a atrocidade marcam nossa história desde o berço , não se limitando aos grupos marginais, arredados da lei, mas concentrando-se (e muitas vezes em maior escala) também entre os grupos "legalizados", imbuídos de autoridade, praticantes da "violência autorizada", legalmente amparada e, portanto, aceita, sob pretexto de "um bem maior", que é a tranqüilidade da nação, das "pessoas de bem", que confiam no poder da "justiça" e, assim, não questionam os métodos empregados. (ALVES, 2013, p. 124)

A violência existente desde o berço é uma situação que se apresenta de forma recorrente em muitas obras, seja no ambiente rural ou urbano. Alves inicia com um questionamento sobre essa condição humana:

Como explicar que no núcleo urbano, na corte, formem-se meninos, posteriormente homens, cruéis e sem limites, tal como acontece no sertão? Como entender a explosão da violência primitiva e desmedida, mesmo entre aqueles com acesso ao ensino e à ordem? Parece-nos que a causa reside na sociedade escravocrata em cujo seio a violência se assentou como prática "natural" de poder e de domínio sobre o outro, tanto no campo quanto na cidade. (ALVES, 2013, p. 127) 
Por isso, é importante pontuar que a violência não deve ser apenas relacionada com contextos rurais. Na obra Feliz ano novo, de Rubem Fonseca, por exemplo, temos contato com a violência ambientada em espaço urbano. No conto "Passeio noturno - Parte I", um homem chega em casa após um dia de trabalho, carregando uma pasta com seu material de trabalho e o narrador descreve uma cena de uma família em casa, assistindo à novela, tudo que seria esperado de mais um fim de dia. Contudo, a sequência é quebrada quando esse homem pega o carro e vai para rua atropelar pessoas. A mulher ainda questiona o que o marido faz todos os dias passeando de carro na rua à noite. Ao final, a personagem retorna para casa e vai dormir, sendo um encerramento de narrativa diferente do que poderia ser esperado pelo leitor.

Já no ambiente sertanejo, em Terras do sem fim, de Jorge Amado, é possível perceber também situações de violência. Nessa obra, são retratadas as disputas pelas terras de plantio de cacau e sobre a ida de muitos homens para Ilhéus, no que se constitui como uma tentativa de melhoria das condições de vida. Uma das personagens é Damião, um homem cuja profissão era matar:

Sua profissão era matar, Damião nem sabe mesmo como começou. O coronel manda, ele mata. Não sabe quantos já matou, Damião não sabe contar além de cinco, e ainda assim pelos dedos. Tampouco lhe interessa saber. Não tem ódio de ninguém, nunca fez mal a pessoa alguma. Pelo menos assim pensou até hoje. (AMADO, 1986, p. 68)

Ele era jagunço da família Badaró e sempre cumpria as ordens da família, sem qualquer questionamento sobre as ações cometidas. Contudo, ao ouvir um diálogo sobre o seu trabalho, ele começa a sentir-se incomodado com a ideia de matar outros. Era como se aquele homem saísse de uma alienação e tomasse consciência dos seus atos.

Neste trabalho, será analisada a violência no sertão, mas sempre refletindo sobre esses atos como intrínsecos ao ser humano ou a forma como o ambiente pode influenciar aqueles que o habitam, mas sem restringir a uma esfera.

\section{LITERATURA E CINEMA}

A literatura apresenta uma grande importância, tanto para o leitor quanto para a sociedade que a recebe, pois é a partir dela que podemos compreender determinados grupos em determinados períodos e refletir sobre acontecimentos históricos e questões sociais. Culler (1999) explica que a obra literária

É um evento lingüístico que projeta um mundo ficcional que inclui falante, atores, acontecimentos e um público implícito (um público que toma forma através das decisões da obra sobre o que deve ser explicado e o que se supõe que o público saiba). (CULLER, 1999, p. 37) 
Sendo assim, literatura é ficção, mas parte da realidade já existente, mantendo um caráter verossímil, ou seja, uma equivalência de verdade. Além disso, a importância da literatura está, principalmente, no fato de que ela permite que o leitor exerça uma atividade crítica sobre o mundo. Sobre isso, Saraiva e Mügge (2006) explicam que

[...] A obra de arte e, em especial, a literatura podem assumir a função de gerar, criticar e renovar padrões sociais de comportamento, tendo em vista que, pela identificação, provocam a adesão afetiva do leitor, traduzindo, igualmente, o apelo à transformação da própria realidade social. (SARAIVA E MÜGGE, 2006, p. 40)

No âmbito do cinema, Brito (2006) discorre sobre como analisar a adaptação de um romance para o cinema. É importante perceber que, quando se fala da passagem de uma obra literária para o cinema, alguns detalhes devem ser percebidos previamente. Afinal, estaremos tratando da transposição de uma obra cuja materialidade é a palavra, para outra que trabalha com diversos recursos, tais como sons, imagem, entre outros. Na figura 1, retirada de "Literatura e cinema", de João Batista de Brito (2006), é possível ver uma síntese dos processos que podem ocorrer em casos de adaptações cinematográficas realizadas a partir de obras literárias.

Figura 1: Tabela de operações

\begin{tabular}{|l|l|}
\hline OPERAÇÃO & Descrição \\
\hline REDUÇÃO & $\begin{array}{l}\text { Elementos que estão no texto literário (romance, conto ou } \\
\text { peça) e que não estão no filme. }\end{array}$ \\
\hline ADIÇÃO & Elementos que estão no filme sem estar no texto literário. \\
\hline DESLOCAMENTO & $\begin{array}{l}\text { Elementos que estão em ambos, filme e texto literário, mas } \\
\text { não na mesma ordem cronológica, ou espacial. }\end{array}$ \\
\hline $\begin{array}{l}\text { TRANSFORMAÇÃO } \\
\text { PROPRIAMENTE DITA }\end{array}$ & $\begin{array}{l}\text { Elementos que, no romance e no filme, possuem } \\
\text { significados eqüivalentes, mas têm configuraçeses } \\
\text { diferentes. }\end{array}$ \\
\hline SIMPLIFICAÇÃO & $\begin{array}{l}\text { Uma transformação que consistiu em, no filme, diminuir a } \\
\text { dimensão de um elemento que, no romance, era maior. }\end{array}$ \\
\hline AMPLIAÇÃO & $\begin{array}{l}\text { Uma transformação que consistiu em, no filme, aumentar a } \\
\text { dimensão de um ou mais elementos do romance. }\end{array}$ \\
\hline
\end{tabular}

Fonte: Brito (2006)

A partir de alguns conceitos da literatura e do cinema, a análise da adaptação cinematográfica do conto "O duelo" será realizada. Para isso, serão usadas algumas referências como Brito (2006) e Hutcheon e O’Flynn (2013).

\section{O DUELO ENTRE MATERIALIDADES: DA PALAVRA PARA O VÍDEO}


Por meio de um narrador onisciente heterodiegético, é possível conhecer um recorte da vida de um homem que queria se livrar da desonra de uma traição por meio de sangue. O conto "O duelo" trata sobre Turíbio Todo, um homem que retorna mais cedo para casa, após uma pescaria que não teve bons resultados, e todos os atos seguintes na narrativa se desenrolam por esse detalhe. Ele flagra a esposa em situação de adultério e a necessidade de vingança se instaura no texto. Contudo, ao ir na casa de Cassiano Gomes, o parceiro de adultério da esposa, ele mata o irmão de Gomes, Levindo, por engano. Esse ato equivocado faz com que comece uma série de desencontros entre Cassiano e Turíbio, enquanto ambos se perseguem. Durante esse duelo, Cassiano adoece e, quando ele falece, deixa todo o dinheiro para Timpim Vinte-e-um, para salvar seu filho. Quando Turíbio descobre sobre a morte de seu rival, ele inicia seu trajeto para retornar, contudo, é surpreendido por Vinte-e-um que anuncia que o matará e assim faz, cumprindo com a última promessa feita com Cassiano.

A violência a ser analisada nas materialidades disponíveis sobre o conto são apresentadas a partir do contexto da jagunçagem, permeado nessa narrativa por sangue, vingança e mortes. No início da obra já temos um prenúncio de uma possibilidade de releitura da violência. Enquanto no conto os atos violentos ficam muito mais na intenção das personagens, as cenas do filme são recheadas de agressões que mancharam as telas com muito sangue. $\mathrm{O}$ conto inicia com uma breve descrição feita pelo narrador sobre Turíbio, explicando que ele chorava sem fazer caretas e que era "papudo, vagabundo, vingativo e mau" (ROSA, 2015, p. 137). No filme, teremos uma apresentação um pouco diferente, conforme ilustrado na figura 1 :

Figura 2: Turíbio na adaptação cinematográfica

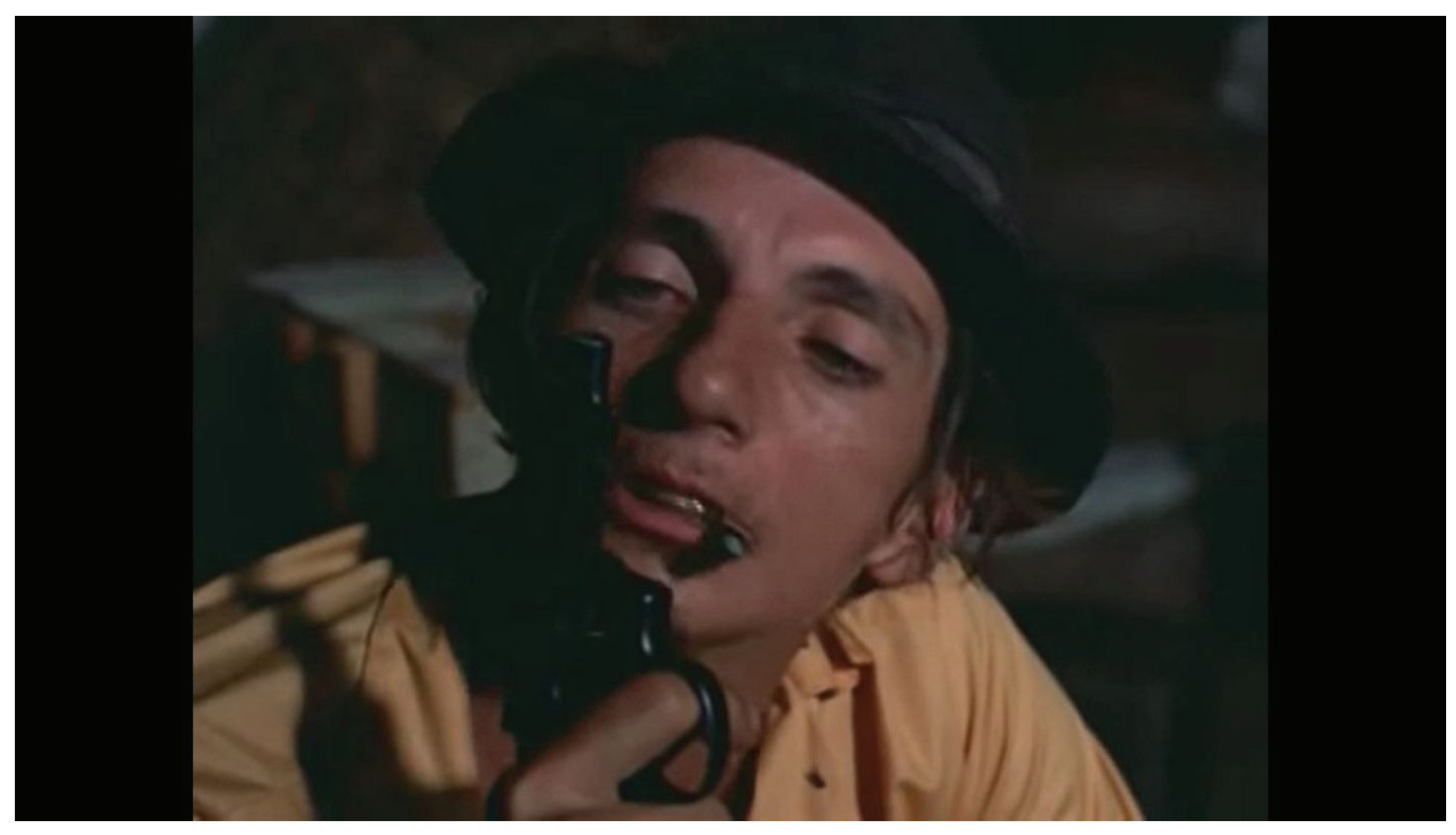

Fonte: THIAGO (1973)

Em contrapartida, a cena que abre a adaptação cinematográfica é uma imagem do personagem limpando uma arma. Apenas utilizar uma narração sobre a personalidade da personagem não parecia o suficiente, um simples gesto de segurar uma arma estava a serviço de deixar uma mensagem clara sobre a conduta de Turíbio. 
Outro ponto importante e que nos remete a violência é o nome do conto: espera-se que ocorra um confronto entre os envolvidos no duelo. Contudo, isso não ocorre efetivamente, já que as personagens não se encontram ao longo da narrativa e da adaptação. Isso gera um efeito de anticlímax, já que o leitor pode aguardar pelo desfecho e que um saia como vencedor. O final é completamente diferente, pois o texto se encerra após a morte de ambos, sendo uma por doença e a outra por assassinato realizado por um terceiro sujeito da história, quase como uma vingança deixada como herança. Em trecho retirado da obra literária, é possível perceber essa ocorrência: "e continuou o longo duelo, e com isso já durava cinco ou cinco meses e meio a correria, monótona e sem desfecho" (ROSA, 2015, p. 147). Essa ocorrência se repete no filme também, já que ambos seguem sem qualquer encontro.

Seguindo, é importante pontuar que vingança e violência andam juntas nessa narrativa, pois é como se a traição da esposa de Turíbio e a tentativa de vingança que acaba vitimando o irmão do amante só pudessem ser pagas com a moeda de sangue. Limpar a honra era o objetivo principal desse homem que não aceitou ser traído. Crimes de honra historicamente costumam dividir opiniões e denunciam uma postura sexista na sociedade, quando trata-se da vingança por adultério, pois demonstra ainda uma delimitação de papéis no contexto familiar. A pesquisadora Lourdes Maria Bandeira discorre sobre isso, ao mencionar que

Em pleno século XXI, os assassinatos de mulheres continuam sendo praticados e têm aumentado, embora não sejam mais explicados oficialmente como crimes de honra. Paradoxalmente, não houve mudanças significativas em relação às razões que continuam a justificar formalmente a persistência da violência de gênero, ainda, centrando-se principalmente na argumentação de que a mulher não está cumprindo bem seus papéis de mãe, dona de casa e esposa por estar voltada ao trabalho, ao estudo ou envolvida com as redes sociais, entre outras. (BANDEIRA, 2014, p. 456-457)

A lei de honra permeia toda a narrativa e guia os atos das personagens. O tipo de crime cometido pelo protagonista é chamado diversas vezes de crime de honra, pois trata-se da vingança pelo adultério cometido por sua esposa, como no trecho a seguir:

Nem por sonhos pensou em exterminar a esposa (Dona Silivana tinha grandes olhos bonitos, de cabra tonta), porque era um cavalheiro, incapaz da covardia de maltratar uma senhora, e porque basta, de sobra, o sangue de uma criatura, para lavar, enxaguar e enxugar a honra mais exigente. (ROSA, 2015, p. 142)

Todavia, ao contrário do que é recorrente na literatura, Dona Silivana não foi o alvo de Turíbio na busca pela restauração da honra, o que é apontado por Bandeira como ocorrência comum. Mas, ainda assim, vale a reflexão sobre o uso de violência para solucionar situações como estas, percebendo o forte desejo de Turíbio por lavar sua honra com o sangue de uma criatura. Em O duelo, quem paga pela atitude do casal de adúlteros é Levindo, irmão de Cassiano Gomes, em ato falho por parte de Turíbio que pretendia matar Cassiano. 
Pensando sobre essa necessidade de vingança e sentimento de injustiça por parte de Turíbio, aparece uma ironia no filme, uma vez que o personagem vingativo que quer punir alguém por um adultério se envolve com uma mulher durante suas andanças. Trata-se de uma cigana que está com um grupo no meio da travessia de Turíbio, sendo estes elementos adicionados apenas no filme. Seguindo a tabela de operações de Brito (2006), essa situação se encaixaria como adição de elementos.

O ato violento de silenciar alguém também é acompanhado durante a obra literária. Dona Silivana sempre é trazida para a narrativa por meio de falas do narrador ou dos homens que compõem a história, como quando ela se sentia preocupada pela situação de Cassiano e é descrito que ela sentia-se mal, tudo por meio do discurso indireto. Diferentemente do vídeo, local em que ela aparece diversas vezes, seja aguardando nervosa pelo desfecho do duelo inacabado ou ainda na companhia do amante. Ocorre uma ampliação do espaço feminino nas telas, como ilustrado na imagem a seguir:

Figura 3: Dona Silivana em um diálogo com Cassiano Gomes

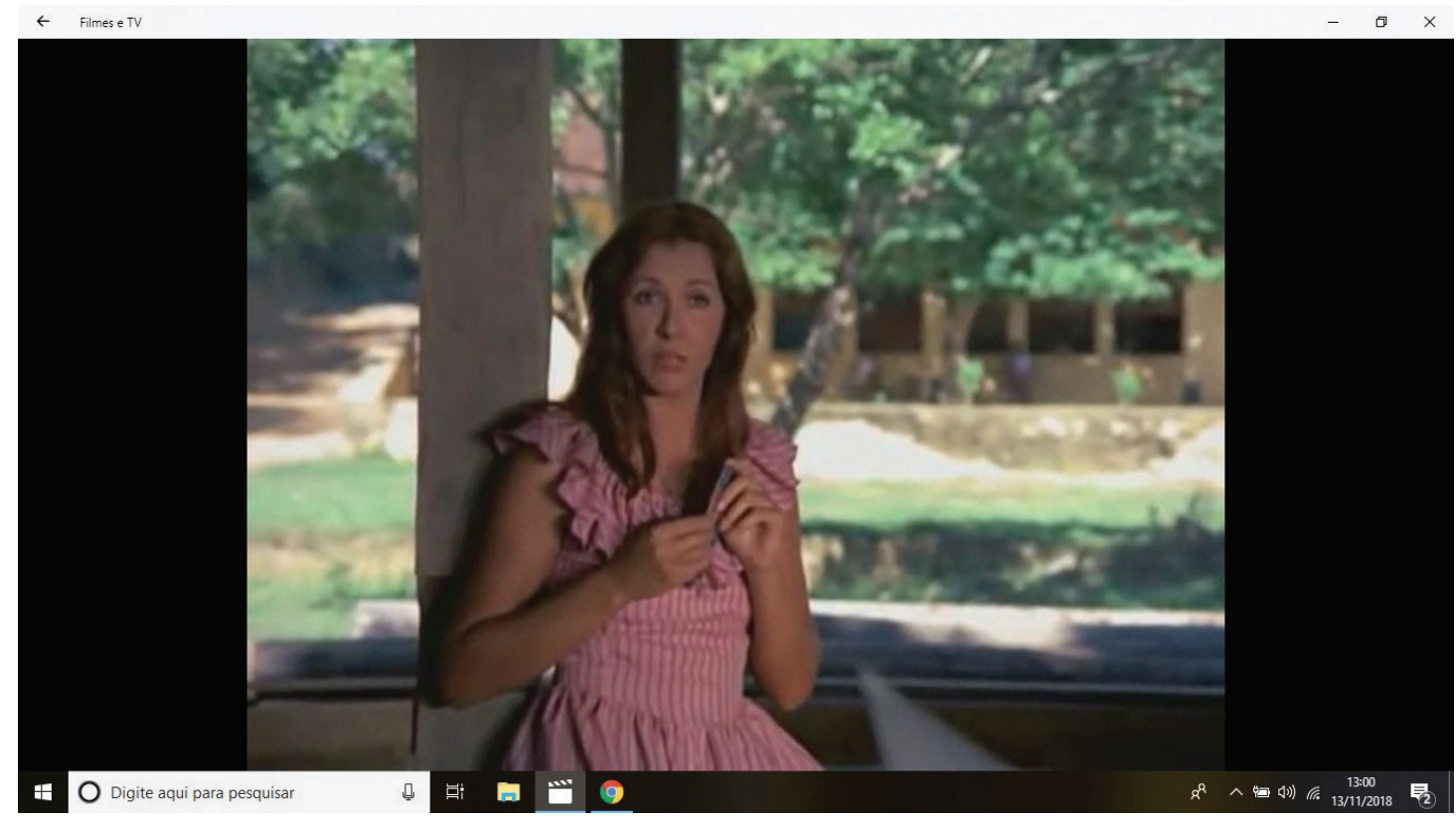

Fonte: THIAGO (1973)

Uma mudança significativa que ocorreu durante a passagem da palavra para o vídeo foi a inserção de outros personagens do mundo rosiano no filme. O filme Sagarana - o duelo, lançado em 1970, em que o cineasta Paulo Thiago realiza uma transposição do conto O duelo, do livro Sagarana, de Guimarães Rosa, ao mesmo tempo em que faz alusão aos contos Dão-Lalalão (O devente) e Cara-de-bronze, pertencentes aos livros Noites do sertão e No Urubuquaquá, no Pinhém, respectivamente. Além disso, a personagem Titão Passos, de Grande Sertão: Veredas, é adicionado em uma cena.

Nessa ideia de inserção de personagens, um grupo de ciganos também é adicionado à trama, pode remeter aos personagens do conto "Corpo fechado", também publicado em Sagarana. Manuel Fulô é questionado sobre já ter vivido com os ciganos, que ele responde: 
Foi por causa que eu estava sem gosto p'ra caçar serviço bruto, naquele tempo... Garrei a maginar: o que eu nasci mesmo p’ra saber fazer é negócio de negociar com animal. Mas eu queria ser o melhor de todos... E quem é que é mestre nessa mexida? Não é cigano? Pois então eu quis viajar no meio da ciganada, por amor de aprender as mamparras lá deles. Me ajustei com um bando... (ROSA, 2015, p. 241)

Os ciganos não desempenham um papel muito grande nas cenas, mas são recorrentes mesmo assim. A traição que Turíbio comete somente no filme é com uma das ciganas. Na imagem a seguir, uma das cenas é trazida para ilustrar essas personagens.

Figura 4: Grupo de ciganos inseridos no filme

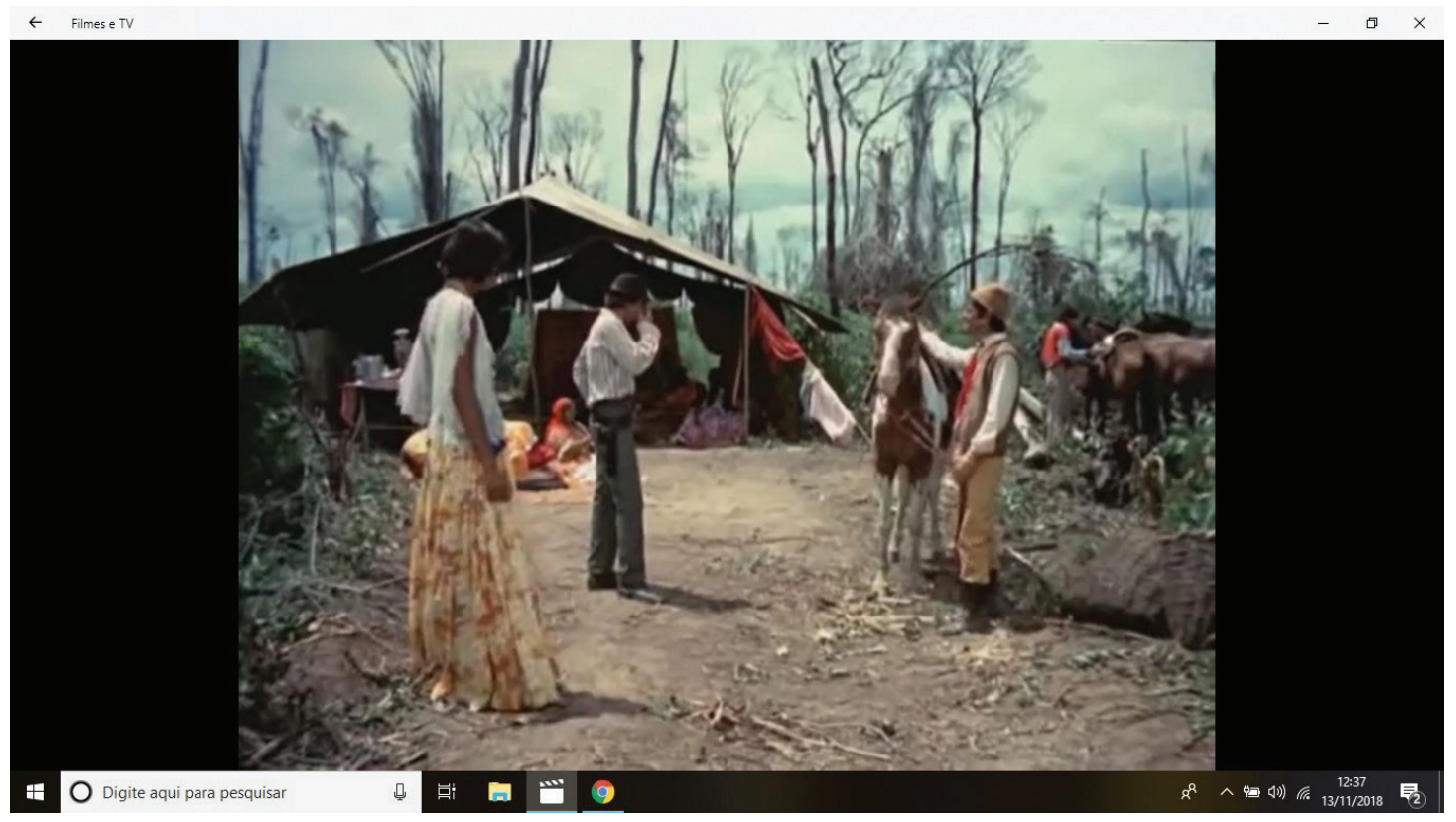

Fonte: THIAGO (1973)

Outra cena adicionada foi a de umas das ciganas lendo a mão de Turíbio, o que confere até uma importância do grupo para a sequência. Ela menciona sobre duas linhas que parecem que vão se encontrar, mas cada uma segue seu caminho, explicando que seria a linha da vida e da morte. É possível refletir sobre o duelo também, em que Cassiano e Turíbio andam pelos mesmos lugares, porém sem se encontrarem.

A passagem de conto escrito para filme contou principalmente com a operação de adição de elementos. Dona Silivana ganhou mais espaço, a arma e o sangue que manchou a tela em diversas cenas serviu como forma de enfatizar a violência contida nas palavras. Além disso, uma homenagem às obras de Guimarães Rosa foi realizada pela inserção de personagens de outras histórias. 


\section{CONSIDERAÇÕES FINAIS}

Literatura e realidade estão intimamente ligados, seja por retratar uma sociedade em determinada época, por refletir sobre a condição humana. A obra de Guimarães remete para um contexto de jagunçagem, bem como de modernização decorrente da construção da cidade de Brasília. Mesmo com as melhorias chegando, ainda é possível notar que nem tudo chega a todos os lugares. A falta de acesso à educação e à segurança é um aspecto que ficam nas entrelinhas nessas grandes histórias.

Pensando sobre essa segurança que ainda não é efetivamente garantida pelo Estado, cria-se uma ordem, a lei dos homens, e é por meio dela que a justiça é feita. A violência no conto "O duelo" pode exemplificar isso. A traição é resolvida por meio de vingança, o crime de honra é realizado. Nas páginas, as ameaças, a raiva apresentada por meio da palavra, enquanto que no filme as armas e o sangue fazem esse papel. O silenciamento da mulher na obra também é percebido como um ato de violência. Nas cenas do filme, esta mesma mulher ganha espaço e voz.

É fundamental assegurar que o signo da violência seja visto não como algo exclusivo de um ambiente sertanejo e retirado, mas como algo presente também no contexto urbano. Atos violentos são presentes na sociedade brasileira desde a colonização e foram perpetuados em momentos como na escravidão, deixando cicatrizes na história do país. Seja no sertão mineiro de Guimarães Rosa ou no espaço urbano de Rubem Fonseca, como mencionado anteriormente, a violência é parte da realidade e é retratada nas obras de Guimarães Rosa com certa frequência.

As principais mudanças realizadas do conto para o filme foram a adição de personagens de outras obras, como uma homenagem ao mundo de Guimarães, e maior espaço para Dona Silivana. A violência que ficava relegada a ameaças no livro, passa a ser demonstrada por cenas de tiros, sangue e morte. Por fim, futuras pesquisas podem dar conta de algumas questões que permeiam a obra Sagarana e que este trabalho não pode inserir nas análises. A representação da mulher na obra de Guimarães Rosa é um importante tópico que pode ser estendido em outras pesquisas.

\section{REFERÊNCIAS}

ALVES, Cristiane da Silva. A formação dos homens e a violência em Grande Sertão: Veredas. Revista Literatura em Debate, v. 7, n. 12, p. 121-138, jul. 2013.

AMADO, Jorge. Terras do sem fim. 53ª ed. Rio de Janeiro: Record, 1986.

BANDEIRA, Lourdes Maria. Violência de gênero: a construção de um campo teórico e de investigação. Soc. estado., Brasília, v. 29, n. 2, p. 449-469, Aug. 2014 . Disponível em <http://www.scielo.br/ scielo.php?script=sci_arttext\&pid=S0102-69922014000200008\&lng=en\&nrm=iso $>$. Acesso em: $02 \mathrm{de}$ Nov. 2018. 
BRITO, João Batista de. Literatura no cinema. São Paulo: Unimarco, 2006.

FONSECA, Rubem. Feliz Ano Novo. - [Ed. especial]. - Rio de Janeiro: Nova Fronteira, 2012. (Saraiva de Bolso)

HUTCHEON, Linda. O’FLYNN, Siobhan. A Theory of Adaptation. 2. Ed. New York: Routledge, 2013.

KUN, Marinês Andrea. CONTE, Daniel. OLIVEIRA, Ana Paula de. O invasor: espaço urbano e violência. Disponível em <http://revistas.fw.uri.br/index.php/literaturaemdebate/article/ view/839/1529>. Acesso em 04 de set. 2018.

LINS, Álvaro. Uma grande estreia. In: COUTINHO, Eduardo. (Org.) Guimarães Rosa. 2a ed. Rio de Janeiro: Civilização Brasileira, 1991. (Coleção Fortuna Crítica) p. 237-242.

O duelo. In: ROSA, João Guimarães. Sagarana. [Ed. especial] - Rio de Janeiro: Nova Fronteira, 2015. (Coleção 50 anos)

O que é literatura e tem ela importância? In: CULLER, Jonathan. Teoria literária. São Paulo: Beca, 1999, p. 26-47.

SARAIVA, Juracy Assmann. MÜGGE, Ernani. (et all.) Literatura na escola: propostas para o ensino fundamental. - Porto Alegre: Artmed, 2006. 344 p.

SAGARANA: O duelo. Direção: Paulo Thiago. Brasil, 1974.

TORNQUIST, Helena Heloisa Fava. Representação da violência e forma literária- Tensões e rupturas. In: Revista Eletrônica Literatura e Autoritarismo - Dossiê nº 10, setembro de 2012 - ISSN 1679-8 49X. 
